\title{
Investigation and Study of the Wind Resistance of Landscape Tree Africa Neem in Haikou City
}

\author{
Wei WEN ${ }^{1, a}$, Guang-Fan LI ${ }^{1, b, ~}{ }^{*}$, Wei HU ${ }^{1, c}$, Xiao-Liang WANG ${ }^{1, d}$ \\ ${ }^{1}$ College of Civil Engineering \& Architecture, Hainan University, Haikou 570228, PR China \\ wwbreathless2014@163.com, 'blgf1728@163.com, 'Yilukuanben1982@163.com, \\ dwayne0509@163.com \\ ${ }^{*}$ Corresponding author
}

Keywords: Typhoon, Landscape Tree, Africa Neem.

\begin{abstract}
On July 18, 2014, in the northeast of Hainan and Wenchang has been hitted by a super typhoon "Rammasun" caused widespread lodging and fold of landscape tree in city proper. Regarded this lodging Africa neem in Haikou city as the research object, investigated and study analysis the reasons why the Africa neem appeared widespread lodging. due to the construction of artificial facilities, directly or indirectly affected on the normal growth and development of root; Under the effect of heavy rainfall, the strength of the surface soil is reduced, the strength of roots-soil composite system was decreased owning to the effect of softening and lubrication of the water on earth; because of the large crown breadth of African neem, it is extremely easily to withstand huge horizontal load and bending moment at the air-soil interface. According to the exposed problem of Africa neem after disaster, put forward the measure that how to improve the Lodging resistance.
\end{abstract}

\section{Introduction}

The urban vegetation is different from the forest vegetation in water conservation, soil, etc. They are mainly reflected in simple community structure, planting small, lack of bush layer and herb layer, obvious differentiation. Wu Xiankun et al [1-4] indicated that urban landscape vegetation play an important role in wind resistance and prevent and combat pollution. Related research focused on the aesthetics of urban landscape vegetation, prevent and combat pollution and the composition of micro climate. But the research on the root below the ground prevents wind is less. On July 18, 2014, super typhoon "Rammasun" go to Haikou by way of Wen Chang city, the wind scale is more than 17 , and the wind speed over $60 \mathrm{~m} / \mathrm{s}$. Every place is a mess after super typhoon. Directly give rise to thousands of landscape tree in Haikou city appeared in lodging and fold. Hundreds of millions of money was lose only in the garden. Fallen trees and branches blocking roads seriously affected people's travel. The shortage of landscape trees in wind resistance was fully exposed by the typhoon. Compared to the trees with developed tap root, the shallow root tree species were more easily appeared in lodging after the occurrence of typhoon and Heavy rainfall.

Many experts and scholars has been researched the roots of trees, mainly concentrated in simple reinforcement and anchorage effect without considering the relationship between the root and the upper structure. Xiao-guang liu[5-8] and other studies have shown that Herb, shrubs and some plant with shallow root system can reinforcement the surface soil, and the plants with developed tap roots can anchor the deep soil; The strength of root-soil complex was increased then decreased with the increase of moisture content. In the face of cross type problems between the different disciplines, academic communication rarely between civil engineering and botany, led the cross research literature of landscape trees in wind resistance was little. Aiming at this situation, the paper briefly analysis the affected mechanism during the typhoon of Africa neem, further expounds the lodging and folding phenomenon. 


\section{The Basic Situation of Africa neem in Haikou City}

Hainan province is the only tropical province in China, classified as tropical monsoon climate, High temperature and rainy in summer, from July to October was the typhoon season every year. July 13, 1991, No. 9106 typhoon landed in Wanning coastal, Wind scale reach 12 level, the wind speed more than $38 \mathrm{~m} / \mathrm{s}, 87$ villages in Hainan province was extremely affected by flood waters, Direct economic loss more than 633 million Yuan [9].On September 26 2005, Typhoon Damrey landed in the northern coastal of Wanning City, wind level 16 , wind speed $55 \mathrm{~m} / \mathrm{s}$, which rarely resulted in Hainan province power outage [10].

\section{Before the Rammasun}

The main landscape tree species in Haikou city including the coconut, casuarinas, Africa neem, Taiwan acacia, the Chinese red bud, camphor tree, fake betel nut, king of Judah, coconut, basin, White laminated, phoenix wood, Fine ficuscunia. Africa Neem as an exotic species, in many parts of Haikou city, roads on sides, schools and parks has been planted. It grown as much as $20 \mathrm{~m}$ of the adult tree, the Canopy were thick and thick, leafy, the length of leaf as long as $5 \sim 15 \mathrm{~cm}$, The crown is larger, it Can be look as a triangle, most of tree-lined cover area after artificial pruning were more than $25 \mathrm{~m} 2$, it Can have a good shade in summer; Under branch height concentrated between $3.5 \mathrm{~m}$ to $6.4 \mathrm{~m}$, The diameter of lateral branch were concentrated on 10 to $25 \mathrm{~cm}$, With an Angle of vertically between $30^{\circ}$ and $60^{\circ}$, most of the trunk diameter is $12 \mathrm{~cm} \sim 56 \mathrm{~cm}$; Due to the limited space, mostly Africa neem were planted in single row, and the planting distance was $5.5 \mathrm{~m}$ or so; the thick roots were visible in surface Soil with around radiation distribution, stretch up to several meters.

\section{After the Rammasun}

Super typhoon "Rammasun" with heavy rainfall, it caused enormous losses to Hainan province. Low areas in urban area was flooded, the deepest water levels has been over $50 \mathrm{~cm}$. The worst hit were Africa neem and the class of Banyan tree, these plants are a massive lodged (fig 1, 3, 4), While casuarina, camphor, coconut and palm in the typhoon were little damaged, mainly including folding branches. The proportion of other tree specials was little. Leaves of most of trees were blown away, only left the bare branches.

After a typhoon, the Africa neem appeared large areas of lodging while the proportion of fold was littler, tree integrity is good, leaves fall less, and keep High density; the lodging direction of African neem was consistent with the typhoon path, figl and fig 4 shows that the level root system of Africa neem was extremely developed, the length of mainly lateral root were more than $3 \mathrm{~m}$, and the root density is higher, tap root is not obvious; the length of roots in the side of the road were shorter than other direction; the soil mainly contained red clay, and the surface soil along with sand; the herbs under the trees were mainly cynodon dactylon, lush growth.

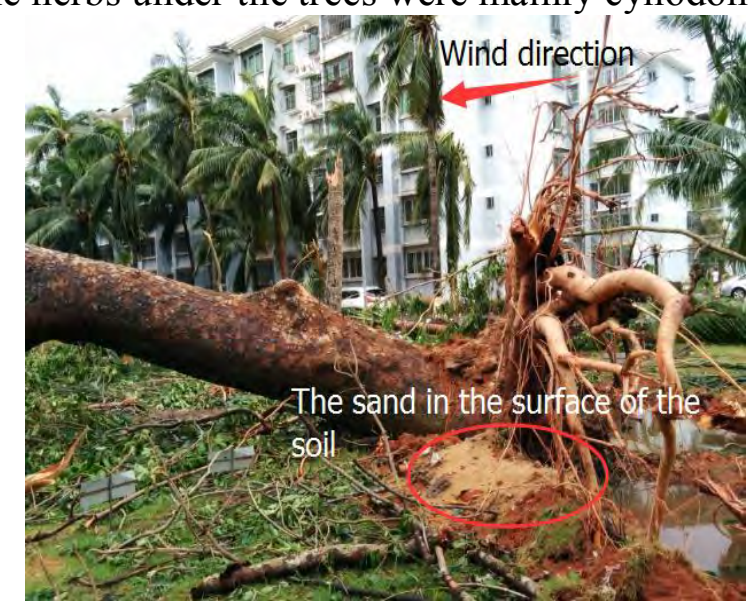

Fig. 1 The lodging figure of Africa Neem

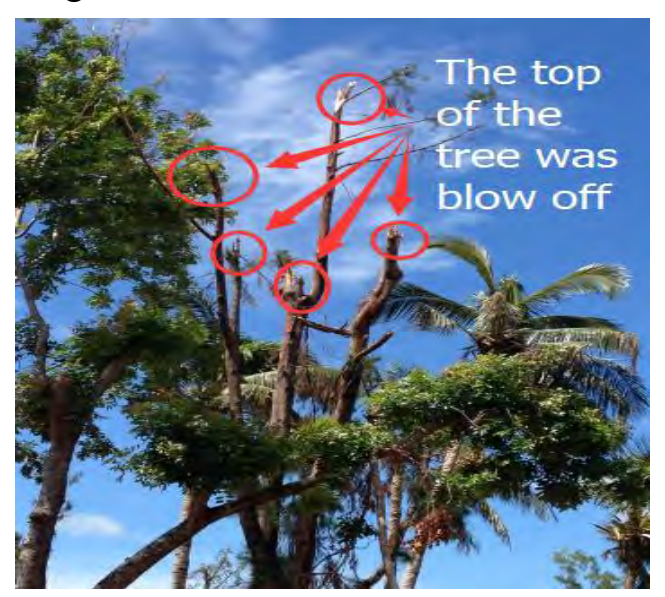

Fig. 2 Folded Casuarina 


\section{Affected Factors Analysis of Lodging African neem}

\section{Factor 1 - Artificial Facilities}

In figure 3 and figure 4 shown that involved artificial influence contains two kinds of the factors relating to include two kinds of meaning: No1, trees planted before the road. In the natural environment, the roots of Africa neem growth evenly spread to around. Because of artificial facilities, the roots of near the roads were cutted, compared with other direction, the length of limited were shorted, formed a semicircle. No 2, road constructed before the plant. In order to ensure the bearing capacity and durability of the road, the subgrade has been compacted with the roller. The compactness of the subgrade has been extremely improved, artificial compaction decreased the porosity of the soil, thus the soil water-holding capacity and ventilation performance has been reduced, increasing the resistance of root growth, affect the efficiency and direction of the root system to absorb nutrients from the soil, and reduced root density and length. Limited direction as the windward side, it is obviously that the canopy will bear huge horizontal wind load, and the wind load must be balanced with the root and soil interaction. The roots of limited surface are shorter and less developed, therefore become the defect of wind resistance.

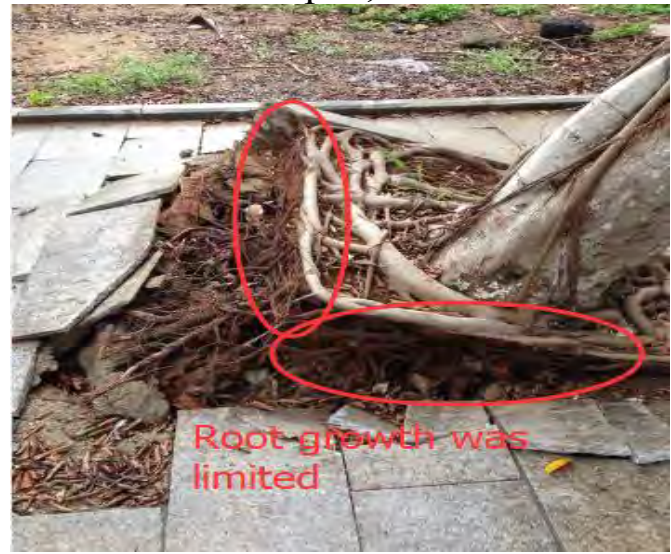

Fig. 3 Root Growth of Flocculus

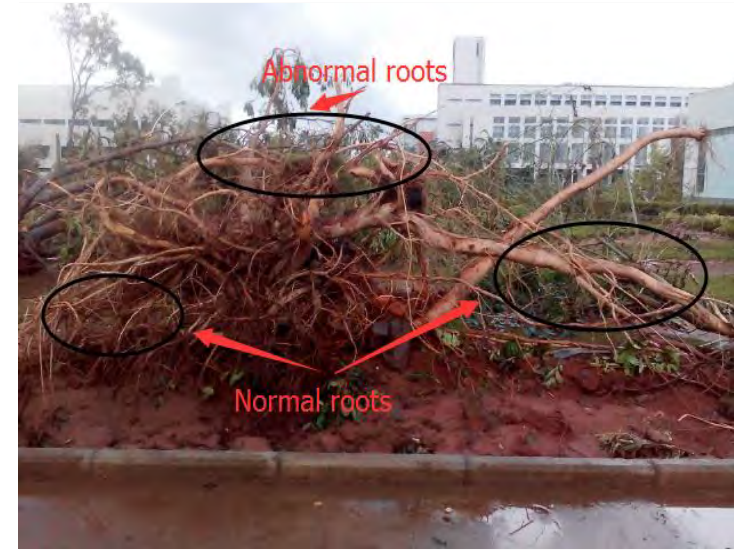

Fig. 4 Root Growth of Frican Neem

\section{Factor 2- Heavy Rainfall}

A typhoon lashed Haikou with strong winds and heavy rains; it has brought serious challenges to drainage system of Haikou city. Limited displacement of underground drainage system cannot meet the needs of heavy rainfall, directly result many places in Haikou city were submerged by water erosion. The scene situation shown that the root depth range from 20 to $40 \mathrm{~cm}$, within the scope of the upper soil layer containing gravel soil, Cynodon dactylon grown very abundance, Makes the porosity of surface soil increased, Interconnected pores provides a convenient channel for rainwater infiltration to deep soil layer, accelerated the penetration rate of the rain, prompting the surface soil entered the stage of saturated in advance, then the soil was softening, the bearing capacity has been reduced; Because of the heavy rain, the soil with little permeability coefficient cannot drained the rainwater in time, as a direct the ground was covered, under the bubble effect of the rain to ground, the strength of the surface soil was lost. So as to make the strength reduced of root-soil complex due to the effect of softening and lubrication of the water on earth.

\section{Factor 3 - Human Subjective}

Super typhoon more than one time every year in Hainan, the intensity was different from each other. In order to guard against super typhoon hit again, part of the canopy trees and landscape were trimmed when they reach a certain extent of the crown not on a regular basis. Reducing the wind damage, and to prevent the tree appearing lodging and folding. In recent years, Africa neem were grown thrive, forest canopy thicker and thicker, the crown is bigger, thick trunks, more roots grown on the surface soil, and the diameter is huge, the length of Africa neem has been over 3 meters. The external manifestation of African neem partly misled the garden workers, leads the staff format a 
wrong view that these trees would not appeared lodging because of its wind resistance very strong, and ignored to trimming the branches of the Africa neem, let it free without considering the typhoon, due to the huge Windward side of Africa neem, so it will bearing huge load that made it lodging.

\section{Factor 4 -Typhoon}

Because of the wind level of Rammasun was very high, huge speed, and the wind pressure was increased along with the level of wind. Therefore, the Africa neem would bear huge load when the typhoon arrive it. Thick leaves can significantly reduce the penetration of the wind; therefore, we can assume the Africa neem as a wind deflector. Wind deflector bears the horizontal force from the typhoon, produced huge horizontal load and bending moment in the ground diameter. The horizontal force and bending moment more than the strength of the root-soil complex near the surface so that the plants were appeared lodging and the roots not snaped at all.

Through calculation of Lipu Wang [11], stress in different height can be obtained. Through calculating formula 1 and 2 , the result can be represented as fig 6 , it shown that the trees in difference height bearing difference wind pressure, the minimum load at the top, and the biggest load at the root. As the wind speed increases, the stress increased.

Assume: the crown of a tree is a regular rotation and the trunk was the center of symmetry (shows in fig 5), the wind heart would be in the center of the trunk line, and the load center in two-thirds of tree height.

The stress in the unit area generated by the wind:

$$
F=\frac{\rho v^{2}}{2 g}
$$

The bending moment on the tree:

$$
M=F\left(Z_{0}-Z\right)
$$

Type: $\rho$ as air density, $\rho=1.23 \mathrm{~kg} / \mathrm{m} 3$, $\mathrm{v}$ as the wind speed, $\mathrm{Z} 0$ as the load center $(\mathrm{m}), \mathrm{Z}$ as the height of the tree.

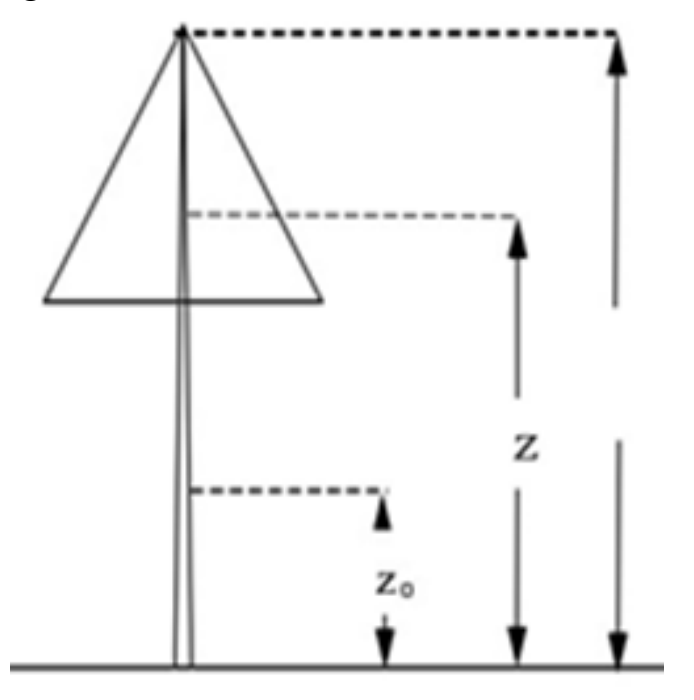

Fig. 5 Plants Calculation Model (south China tropical crop science)

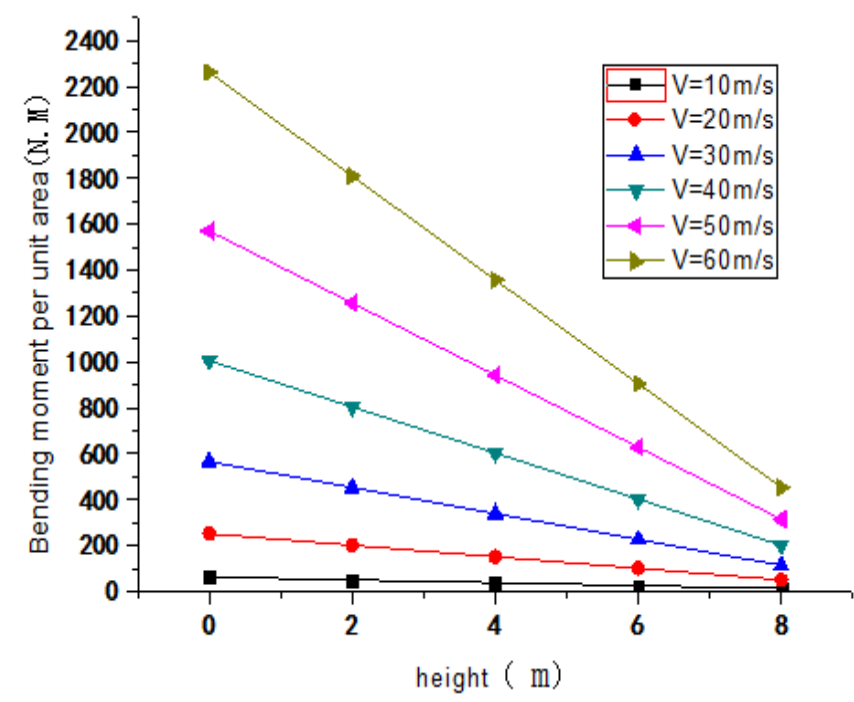

Fig. 6 The Bending Moment Diagram in Different Tree Height and Wind Speed

Through the above analysis we can conclude that the Africa neem was affected by the inside and outside factors, typhoons, heavy rainfall and artificial facilities were the mainly outside factors.

The interaction of the internal and external factors resulting in Africa neem lodging and little appeared broken branches, these factors has important reference value in selecting urban landscape tree species. Now integrated all the affected factors of African neem shown in follow chart: 


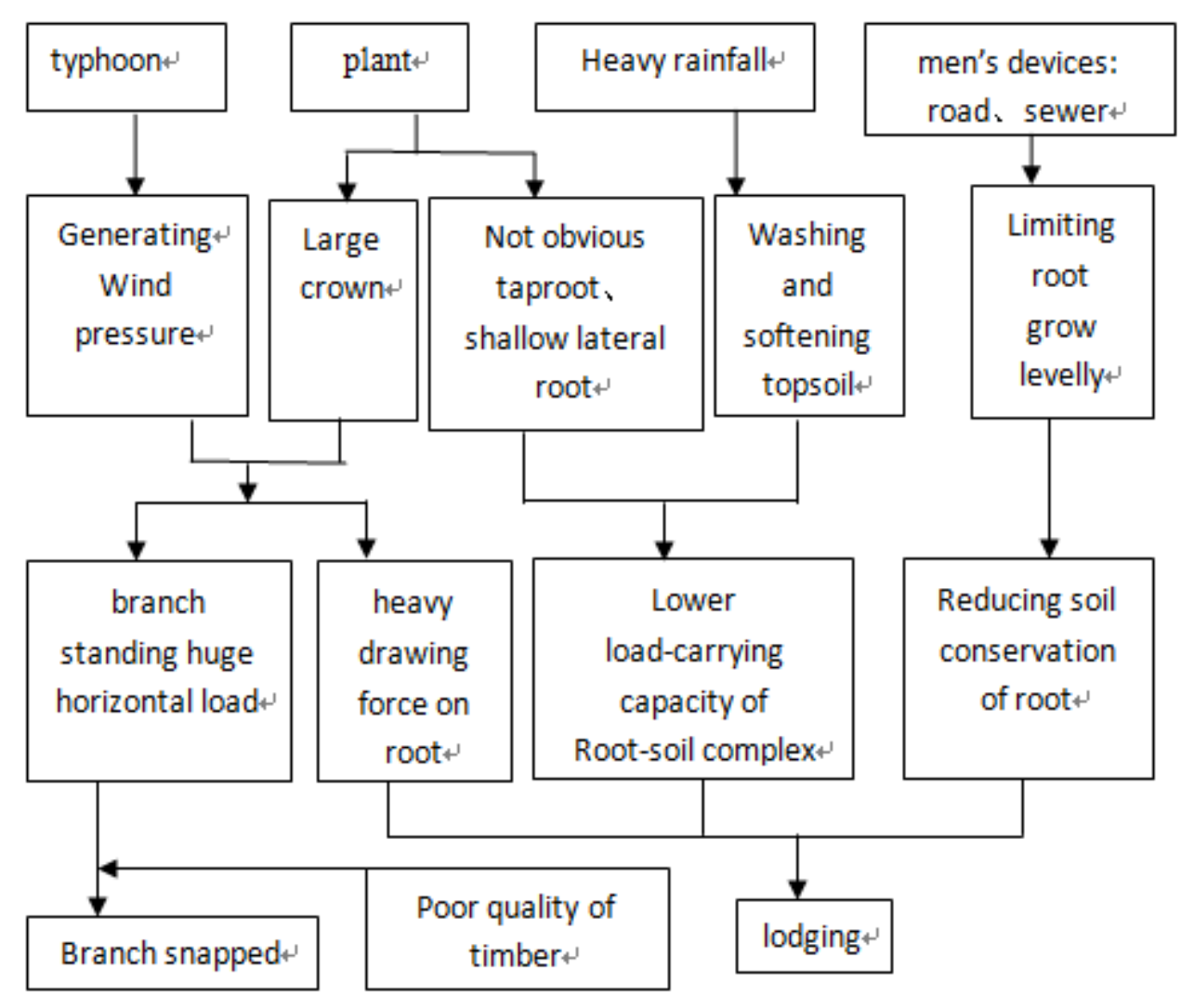

\section{Wind Prevention Measures}

In the city of Haikou, the super typhoon "Rammasun" induced a great deal of fallen Africa neem and Serious ecological destruction, which can be recovered but cannot returned to the original scale. In order to reduce the possibility of the devastation of Africa neem and enhance the wind resistance of Africa neem, we should take the following measures before typhoon:

(1) In tree transplanting, it's necessary to be careful not to damage the main root and prune lateral root, which might timulate root growth toward the soil depths.

(2) Before the typhoon coming, pruning the larger crown African neem periodically could reduce the windward area, which could enhance the penetration of the wind, so that we could reduce wind pressure of crown, and then reducing effect on horizontal force and bending moment of the diameter.

(3) For the trees of slow growth and high economic value can be set the device against wind. The main principle for device is to limit the swing of the trunk, thereby reducing horizontal force and bending moment of the size effect, so that it can improve the lodging resistance of the tree.

(4) If the root system of the Africa neem has been exposed to the surface of the soil, the best thing to do is to hilling up with earth, which could stop the rain to the original surface directly scour and extend the rainwater infiltration path, so then delay the softening process of original overburden; At the same time, ridging above help to increase the root soil pressure and improve the Africa neem resistance overturning force.

(5) Planting trees in several rows could build community structure to improve the overall ability to resist wind.

\section{Conclusion}

This thesis aims at the Africa neem which affected by the larger number and the four main causes for the serious things are analyzed. The growth of root system would be limited for the construction of artificial facilities (such as road drains), which could make the windward side root growth length smaller and reduce the effective solid soil range. Under the effect of heavy rainfall, the soil surface strength would decrease, and the strength of root-soil composite decreased with water softening. 
Hainan's climate is typical tropical climate characterized by hot and rainy summers, which is beneficial for growth of plants, especially for the Africa neem. The mature Africa neem has developed root system and exuberant growth of branches, which give garden workers a false impression that it has strong ability against the wind, so there is no need to prune the tree before typhoon. This is a serious mistake that would make the base of the Africa neem bear enormous moment and pushing force transmitted from the top of the tree. The comprehensive effect of these factors could flatten the Africa neem with roots not broken. According to the problems of the Africa neem that come to light in this typhoon, this article combining with the actual situation puts forward some measures to improve the ability against the wind of the tree.

\section{Acknowledgement}

This work was financially supported by the National Science and Technology support plan for twelfth five years of China [No: 2013BAK05B03]; the Midwest Key Areas Construction Project Plan of Hainan University.

\section{References}

[1]Wu X K. The Influence of Typhoon in Shenzhen City of Landscape Plants and Countermeasures [D]Nanjing Forestry University, 2007.

[2]Tian L J, Jiang M Z. Trees lead absorption and accumulation to the traffic [J]. Environmental Engineering, 1984, 06:54-56.

[3]Wang Z L, Yin C Z. Creeping bentgrass grass roots of urban sewage purification effect [J].Journal of grass industry, 2005, 04:89-93.

[4]Liu L F. Shenyang road lined with trees application is analyzed [J].Science and technology to become rich wizard, 2014, 05:186.

[5]Liu X G. Tree roots and soil friction anchorage performance study [D]. Beijing Forestry University, 2013.

[6]Xie M S.Tree roots fixed slope soil mechanics research [J].Journal of soil and water conservation, 1990, 03:7-14+50.

[7]Song W F, Chen L H, Liu X P. Trees root reinforcement effect of experimental research [J]. Research of soil and water conservation, 2008, 02:99-102+106.

[8]Zhang X L, Hu X S, Mao X Q, etc. Loess area in the northeast of Qinghai-Tibet plateau slope protection shrubs Karaganda korshinskii roots drawing friction experimental study [J]. Journal of rock mechanics and engineering, 2011, S2:3739-3745.

[9]Information on http://wenda.tianya.cn/question/13c79eb6a730ebf2.

[10]Information on http://news.sohu.com/20050927/n227066154.shtml.

[11]Wang L F. Economic forest meteorology [M].Yunnan: Yunnan science and technology press, 1995, 187-194. 